DE DE GRUYTER OPEN
Journal of Intercultural Management

Vol. 7, No. 4, December 2015, pp. 55-67

DOI 10.1515/joim-2015-0030

Maldonado Alcudia Ana Virginia del Carmen ${ }^{1}$

Universidad de Occidente, campus Mazatlán, Sinaloa, México

Maldonado Alcudia Cesar Miguel ${ }^{1}$

Universidad Autónoma de Querétaro.México

Maldonado Alcudia Minerva Candelaria ${ }^{1}$

Universidad Autónoma de Querétaro.México

\title{
Employee involvement in hotel total quality management
}

\begin{abstract}
The paper focuses on the analysis of the employees'behaviour, specifically in their involvement and commitment in hotel service after the implementation of a quality management system. When organization fails to involve the employees in a meaningful way, two types of workers could be identified; employees with high efficiency and employees with resistance to change. In this qualitative study, it was observed that if an employee doesn't feel a sense of accomplishment, even when he constantly receives training courses, has incentives or sanctions, it is going to be difficult to get his involvement and commitment with the organization goals. This situation happens because the hotel quality management system is supported by an isomorphism with standardized rules that proceeded or originate from a different context and, in that system the features of the company and workers were not considered.

The case study war carried out in a touristic destiny of sun-beach tourism in Mexico. Questionnaires and semi-structured interviews were prepared to elicit the employees' participation in decision-making process, the employees' involvement and commitment

1 anav_maldonado@yahoo.com.mx; c.maldonadoalcudia@hotmail.com,mm_alcudia@ yahoo.com.mx
\end{abstract}


to achieve organization's quality objectives, the employees' efficiency in production processes and service, and the socialization.

As already stated earlier, the intention of this paper is to develop an understanding of the actual practices that guide the relationships of human resources, when quality is joined as a contingent element.

Key Words: Human Resources, Behaviour, Quality, Hotel Service.

\section{Introduction}

These days, the largest and most important international corporations are looking for a means to market their product/services, by trying to assure the quality of services rather than focusing solely on efficiency in the production processes. Therefore, as a result of an institutional isomorphism, it is very common for regional firms to adopt certain regulations which are developed and standardised by intergovernmental and non-governmental agencies. This is seen as an attempt to achieve legitimacy in their organizational fields and in the global market.

This qualitative study analyzed four dependant variables the decision-making process, employees involvement and commitment to achieve organization's quality objectives, employees efficiency in production processes and service, and socialization.

In the hotels studied, rules were adopted which were different from the existing ones. Because there is no standard in working group's behaviour, the intention of this paper is the understand the actual practices that guide the relationships of these groups, when quality is joined as a contingent element.

Among the results, it was observed that the workers' sense of accomplishment was the main factor in influencing their attitude, commitment and participation in aspiring to provide quality services to hotel guests. Even though the strategies employed by management did facilitate international recognition and competitiveness, it is the individual workers who ultimately make or break the reputation for quality.

\section{Quality by an isomorphism in the organization}

Conformity to institutional norms, the structure and behavior of organizations are changing as a result of an isomorphism, "a constraining process that forces one unit in a population to resemble other units that face the same set of environmental cognitions" (Di Maggio and Powell, 1999:108) This means that standardized rules created by governmental, non-governmental organizations and the biggest enterprises are adopted by regional organizations to obtain legitimacy for themselves in their organizational field.

Standardized rules, norms and routines avoid conflict in efficiency levels because they define prescriptive and obligatory goals and designate the appropriate way to 
pursue them. They also reduce uncertainty and ambiguity. The power of rules to predict situations in the environment of organizations forces them to implement strategies necessary for integration.

The isomorphic change, or the process of homogenization, is the tendency to make decisions more in response to the rules of the organizational field, rather than taking into account the productive activities and actual needs of the enterprise (Sotomayor, 2002). Generally organizations are looking to adapt to their organizational environment; sometimes organizations assume an active role in conforming to that environment. Moreover, powerful firms absorb small enterprises which then have to adapt their relationships and their structures. In this way organizational shapes are maintained and the rules of the more powerful firms will prevail.

However, in spite of the best efforts of management, frequently there is a gap between the integration of institutionalized rules in organization quality decision making, and the efficiency of processes and human resources behavior. Failure to institutionalize quality causes negative effects in organizational form, frame, production processes, human resources behaviour, relationship between employees and customers' perception.

The concept of quality has been studied by different disciplines over time. This concept has been linked to the product, manufacturing processes, and process control and quality assurance; and from the 1990's this concept has been linked with total quality management focused of meeting needs and expectations of the consumer.

There is no consensus among researchers on how to conceptualize or operationalize the quality construct; they are focused on different aspects of service quality like excellence, value, conformance to specifications, and meeting or exceeding customers' expectations. The first two views of quality are problematic, defining quality as excellence is subjective and provides no practical guidance for improving quality, defining quality as value captures tradeoffs between excellence and costs, but other attributes of importance to consumers may be ignored. Furthermore, quality as value blends excellence and worth, resulting in a hybrid concept of affordable excellence (Kahn, 2002). While products and services have different characteristics, nevertheless it is important to provide services to the customers who want it, where they want it, and in the quantity and at the price they want it, with higher value added, which consists of additional benefits, and uniqueness in services.

Several models of quality have been developed trying to satisfy the customers' needs and expectations, most of them designed for the manufacturing industry, not for the service industry. This is understandable in light of contributions that both the primary and secondary industries generate to global GDP. However, in the 
context of globalization, there is now a marked trend toward increased importance of the tertiary sector, i.e. service sector.

However, as this study shows, there are factors which inhibit the development of quality services. One of these is a concept known as organizational anarchy, where workers circumvent the rules. Such anarchy is characterized by problematic preferences, unclear technology, and fluid participation (Bendor, 2001):

- Problematic preference: Problematic preferences mean that the organization as a whole does not have a preference ordering of the kind assumed in the theory of choice.

- Unclear technology: Unclear technology means that the organization's own processes are not understood by its members. Members know the goals to achieve, but do not know the means to achieve it.

- Fluid participation: This means that the decision-makers for any particular kind of choice change capriciously. All interest groups have opportunities to impact decision-making, in some cases, how decisions are made is dependent upon the participants.

- Indeed, in this study, we saw inconsistency in the hotel employees' behaviour, the targets were ambiguous, the decision making processes were contradictory and diffuse. This resulted in employees working on their own ideas, and in developing their own set of values and sense of achievement.

Regarding organizational anarchy, Gámez (2007) says "Although the workforce has a degree of professionalism in organizational anarchy, often there is no consistency between their position, role and technical training. It is know-how and experience of the worker that become the criteria for decision-making, but this is not systematic and nor with an established order". After all, the weakness of the scheme is the low productivity and low capacity to creatively impact on the environment. This produces a permanent system with structural imbalances and with some ability to survive the external challenges, but with very little likelihood on such cases, workers exert influence on their colleagues, with mixed results.

The commercialization of hospitality in a market that offers a high diversification and differentiation, forces companies to devise strategies to ensure their permanence, positioning and acceptance. They look for simple solutions in the process of adaptation.

Hotels need to legitimize their natural markets, which in the case of Mexico, involves the United States and Canada. As potential producers of quality services, hotels must identify the methods clients use to obtain information on how to select an establishment before they travel.

There are some international agencies that guarantee customer satisfaction by stating that the hotel services they promote offer the highest quality standards in the field. 
Quality management in enterprises is based on homogenization and on the recognition given by the certification of those agencies, in accordance with the established rules, regulations and standards. The institutional isomorphism is a way large corporations use to dominate other organizations. Regional enterprises accept being dominated because they are motivated to participate in open markets, and to operate with certain competitive advantages.

Hotel quality management is supported by the standardized rules that proceeded or come from the institutions. This means that the enterprises must achieve some changes in their frames, processes, policies etc. Those changes are homogenized with the firms, so they are designed to work in other contexts, and in other realities; then organizations are constrained by institutional arrangements and it is harder to achieve their particular goals. Example: When an employee in a certain hotel shows good attitude with the internal or external clients, it is because he has received special training and has appropriated the organizational culture. The employee's behaviour could not be incorporated or transferred to another company if it is not understood what process was followed to create that behavior.

\section{Quality management in hotel service.}

According to Juran (Juran, 1951), hotel quality is manifested in excellence of service, where there is no allowance for mistakes in any of the tasks. The best facilities offer cleanliness, luxury, good conditions, investment in staff training, provision of materials for the optimal execution of their duties. It does not assume total satisfaction of customer expectations, nor is the focus on identifying what the customer expects about product and service.

Mexican hotels have been rated from outside Mexico, by applying internationally recognized criteria and parameters depending on the size of the organization and the luxury of their facilities. Among the classifications legitimized since the 1970's is the widely recognized rating of gran turismo, five stars, designating luxury, deluxe, first, second and budget hotels.

Globalization has created an atmosphere of high competitiveness in organizations engaged in providing alternative accommodation, such as timeshares. In view of this situation, some hotels have made some changes not only in adapting their production processes, but in substantially diversifying and differentiating their product in order to achieve anticipated profitability. In addition to offering conventional services such as accommodation, food and beverages, some hotels offer gambling, museums, time-shares, etc. All these services make the environment more complex. Resorts Condominium International (RCI) is the agency responsible for assessing the quality of time-share hotels, a situation that leads to such organizations making more adjustments in their structures and processes, through quality management according to the standard guidelines in 
order to obtain recognition; each organization should manage quality according to its own characteristics, but also in accordance with the guidelines outlined in either ISO 9000, RCI or Mexican Nom's to name a few.

Both social and work relationships between employees are retained because they are necessary for coexistence within the organization. That is favorable for all those looking for strategies to perform their tasks quickly and efficiently. Some employees learn from others who have the experience and know how.

Work processses are based on employees' knowledge, experience and in routines, so when a contingency element affects those routines, it creates an adjustment, but only if it is understandable. If it is not understood by the employees, conflict results.

Another point is that good profits impact favourably on job security, which in turn provides economic stability for workers and their families.

When enterprises manage quality in such a way, it follows that quality management differs from the desired organizational objectives, causing confusion among their own staff. Often, the new rules or standards modify work processes, incorporating different equipment, programs, and new forms of control with penalties and even dismissal. Even so, groups of workers do try to act according to the demands of the strategic apex in this environment of ambiguity, either by vocation of service, or under pressure. Staffs establish agreements, coalitions and negotiations among themselves, these then are respected and govern their actions in the organization.

\section{Methodology:}

This study was based on qualitative methodology, the case selection were ten five star's hotels in a touristic destiny of sun-beach tourism in Mexico. A multiple case study research design was needed for in-depth analysis of the implications of quality management of the hotels with different characteristics. The hotels were selected on the basis of distinctive quality already obtained, quality program, and age in the marketplace and growth. One of the hotels has three quality certifications provided by national and international institutions, the other nine have those distinctions and one certification although they don't have a specific program for quality.

The research was focused on workers in the Room Division area, in Reception, Telephones, Housekeeping and Reservation departments. Employees in these groups cover the contact with guests from the moment of check in until check out time. The field research was carried out with interviews with the various actors involved in selected departments, direct observation, and review of internal documents of the organization as well as external ones.

The response of human resources was analyzed, as they were faced with a new system of quality management in which the organization adopted rules oblivious to actual prevailing conditions. In fact, the new system did facilitate the hotels' recognition, legitimacy and international competitiveness, but at some cost to the individual worker. 
The study took the shape of a transversal cut (Méndez etal., 1986). The information was captured through questionnaires and semi-structured interviews. In qualitative studies, it is important that the subjects have the same basic characteristics in order to protect the internal validity of the subject selection process (Hatch \& Lazaraton, 1990).

The questionnaires were carried out with 50 operative employees in the hotels, (12 receptionists, 8 telephone operators, 16 chambermaids, 8 reservations employees, and 6 concierge employees) and the semi-structured interviews to 6 strategic executives and it was very important to built the rapport with all those people.

26 questions were prepared to elicit the four dependent variables considered: a) the decision-making process, b) employees involvement and commitment to achieve organization's quality objectives, c) employees efficiency in production processes and service, and d) socialization. The independent variable is the quality system.

In order to explain the results of this case study, the findings will be set according to each of the mentioned dependent variables.

\section{The decision-making process.}

Decision-making in hotels is centralized in the strategic apex, however if the organization wishes to guide the production activities of service toward quality, it is necessary to delegate certain decisions to the operational staff. These decisions are selected from a pre-determined set of alternatives, in order for the organization to maintain greater control. Simon (1988) refers to decision-making personnel operating in organizations; he argues that the administrative processes are decisionmaking processes, which consist of identifying and separating certain elements in common decisions frequently made by staff members of the organization. These administrative processes establish regular procedures and communicate them to staffs who take part in those processes. The options available are made known to employees in such a way that they can respond with efficiency in any situation. However; this range of possibilities is already formulated by the strategic apex. Alternatives chosen by the employees are chosen under the perception that they are actually making decisions, but in fact the alternatives have been formulated at the administration level with no information regarding the employees' own criteria. Simon appoints that this way of delegating decision-making sets decision- making limits for the employees.

When employees make decisions over the production processes of the service, they make decisions for ordinary situations according to the instructions received, or the standards established in the organization for such cases. For example, when a problem arises, the employee must go to his immediate superior to resolve it. In an unusual situation, (let's say if the boss is absent that day) then expert knowledge is used in an informal way. 
According to Mintzberg, (1979 Moreno, 2001) decision making processes involve developing high quality information. This will address things that can be done, tasks that need to be done; tasks intended to be done, authorized alternatives and their implementation. Even though the employees are not financially remunerated according to their performance, if the organization has succeeded in human resources appropriate the culture of quality, they will make satisfactory decisions for organization purposes. Contrary to this, when the employee is not identified with the culture of quality of the organization, is not familiar with the idea of achievement and objectives of the organization or does not have sufficient information, then that employee prefers not to be a decision-maker. This is because if the decision he makes is quite correct, it passes unnoticed. However, if it was a bad decision he will be punished according to the severity of the result of any bad decision. Responsibilities and obligations of workers, as well as sanctions, are written into the rules of organizational procedures.

\section{Employees involvement and commitment to achieve organization's quality} objectives.

Employees work in the framework of policies and standards set by the organization, while understanding the sense of authority, their space for individual and equipment freedom. "Participation is the mental and emotional involvement of a person in a group situation which encourages him to contribute to group goals and share the responsibility"(Davis, 1999:246). The involvement is psychological, the person involves ego, the contribution relates to giving employees sufficient authority which allows them to release their initiative and creativity. It's quite different from obtaining their consent, because a person who consents doesn't contribute, but merely follows the rules in an automatic manner. Participation is more than just obtaining consent to something that it has already been decided. Participation increases motivation, and when individuals feel part of an organization they want to see it successful. When an employee is involved in achieving the organization's goals and their self-esteem and job satisfaction rises, conflicts and tensions are reduced, staff turnover and absenteeism decreases. When employees feel that they are in the right place, it is also becomes a source of power, because it is not necessary to wait for promotions in order to make significant contributions. The commitment or loyalty of employees is measured by the extent to which they are attached psychologically with the organization and want to continue participating actively in it. It is reflected in their attendance and punctuality to work, seniority in the job and the effort they make to comply with the goals of the company, even exceeding the limits of their duties. If an employee is dissatisfied in the workplace, he does not accept commitments and seeks opportunities to make a physical withdrawal (unauthorized absences, early departures, failure to comply with standards, laziness, etc.) When 
quality is understood, workers develop their creativity and initiative each and every time, because even though there are standard procedures and phraseology to follow, the worker can change the procedures, giving the consumers the freedom to make the request in their own way. Speed doesn't always ensure quality. For example, when hotel reservation clerks are forced to limit their telephone conversations with potential guests to a certain number of minutes, it is not possible for them to give the best perception of the hotel services.

\section{Employees efficiency in production processes and service.}

The clarity in organization objectives about quality management will be reflected in efficient production processes of service. The process, activity or basic task suggests a transformation of inputs into outputs, providing value to the activities that take place in that transformation. The production process is a sequence of elementary processes with multiple relations oriented towards the customer.

The orientation of the processes towards the customer must be transferred to the set of the organizational policies, to programs for continuous improvement and innovation. The formalization and standardization of processes and products provide specifications usually documented in manuals about how activities or processes run, in which flexibility is the right balance to achieve efficiency. The hotels studied have manuals, but they do not respond to the current realities of the organizations, so their obsolescence and innovations in the productive process produce chaos in the roles of workers. The behavior assumed by workers is merely to meet the specifications and instructions of the work. Even when the hotel holds quality certifications, due to carrying out standards in certain processes, efficiency is not achieved in all cases.

One of the factors that impede efficiency is the employee's resistance to change, especially when no one takes into account his work experience in the design of trials. Change is not always welcome; it represents fear of the unknown, in most cases caused by misinformation, and it is also about threats to job security, because the changes are accompanied by sanctions. Workers are subjected to organizational dynamics through various mechanisms controlling them directly and indirectly, as the organizational hierarchy demands rules, procedures and incentives that are perceived as out of proportional to the contributions requested. When the trust placed in them meets their expectations to feel part of the organization beyond hierarchies, procedures and wages, a better work environment is created. In addition, the opportunity to interact with co-workers is another factor to achieve efficiency and provide quality services. When staff of the organization share common values, such as their tastes, preferences and interests, an organizational climate is established in which the exchange of knowledge and experience flows naturally. 
Another factor to consider is turnover; one of the quality policies in these organizations is that they prefer to hire inexperienced young staff. Rather than hire people who come with bad habits, these hotels prefer to train the new recruits themselves. This practice is more common in the departments that have face to face contact with the customer. However, as the average tenure in these type of positions is one year, this has an obvious impact on the quality of service.

\section{Socialization.}

Social relationships arise through associative primary mechanisms (standards, status, role)and joining with psychological elements; Individuals are looking for a relationship that will help their individual

Reciprocity is an indispensable component in this type of relationship, and the parties involved will establish mutual obligations through status, means, and similar aims. The organization is not an entity isolated from its context, the culture of the society in which it works affect it internally and externally; Culture provides individuals with cultural norms which enable them to live their lives according to the predictability of these norms. Culture defines the critical relationship which underpins and perpetuates society. The rules may vary from one area to another, but the role of culture remains constant. The norms define the nature of social and labor relations; the definition source lies in the system of ideas and values of each culture. The rules not only defines what a person should do, while limiting the interaction content, they also create in the individual a sense of obligation, a sense that he must act in a special way or manner.

When the standards established in the organization change their employees' usual way of doing things, this will cause discomfort, but generally operatives will attempt to carry out them, especially if there is supervision. However, if the organization fails to involve the employees in a meaningful way, then those employees will subsequently return to their old way of doing things.

If the organization has succeeded in consolidating an organizational culture, and members of the groups are identified with it, then the socialization in formal working groups is characterized by partnership, cooperation and flexibility. The working environment is pleasant and it also affects social relations of the same groups outside the organization.

In contrast, rigid organizations seeking to achieve certain standards of quality are characterized by lack of empathy among members of the working group, and the focus becomes the conflict among them. For example; in an organization which recognizes the individualized work, rather than the work of the group as a whole, workers guard their knowledge with zeal. They are not willing to share that knowledge with co-workers. Competitiveness among employees is fostered by certain ill conceived strategies by the management, which inhibits sharing. This is 
particularly noticeable when an employee is given monetary incentives to stand out from colleagues. This emphasis on the individual gives those workers the power to obtain benefits and advantages, which can be monetary gain or favouritism from the boss.

\section{Conclusions}

It was noted that the selected establishments are creating organizational manuals after 15 years of operation, and they have each formed a project group to develop the manuals. However, technologies have been incorporated for efficient service production processes without first having analyzed their actual situation.

Regarding quality management, as Del Castillo writes (1996) "on many occasions the goals and objectives of an organization are put in the background as long it can survive or grow," referring to the process in which companies set aside the objectives and goals of an organizational culture characterized by their own values, in order to participate in a larger market.

The values that should be institutionalized to inculcate a culture are reduced by organizational dynamics in which the companies are involved in an effort to appear legitimate in the external environment.

Therefore, these hotels cannot affirm that quality management has focused on customer expectations when they are only aiming to satisfy evaluation criteria imposed from outside the company. Workers are only too well aware of this situation, as they make a show of following the new rules. They need to appear compliant, while in fact they go about their routines in their own way.

Two types of groups of workers were identified in this research; Formal and informal, this classification distinguishes formal working groups such as those human resources that are involved in the same work processes, which share space and resources. Informal working groups are those found within the same space sharing ideas, tastes, preferences and interests, which lead them to establish links and social relations beyond the limits of space on the organization.

It was identified that employees with greater seniority within the organization are the ones who have the know-how, enabling them to offer a satisfactory service to customers. This is in spite of not having manuals, being blocked from promotion and even being resistant to change.

Workers who come face to face with clients are the newly hired employees in the organization and those are the ones with the highest turnover. This high turnover rate negatively impacts on quality services.

The motivation of employees is related to their aspirations for better living conditions and working conditions. In terms of their private life, it is expected that the organization will provide a wage that allows them to live with certain comforts, and while working, to enjoy the same benefits as the rest of the staff regarding promotions, incentives, and pay raises. 
Workers who do not identify with the efficiency goals and company quality tend to perform mechanically at work, because they are suddenly plunged into a series of standards, policies that are far from their daily life, their values, and their knowhow. They may follow the established standards but never fully integrate them into the organization. There is no consolidation of a culture of quality.

Workers, in which there is a clear definition of the organization's goals and prevailing values, always act in the same direction towards achieving targets, even if there are factors that suppress their better performance. These factors may be outdated manuals, outdated programs, and low wages, among others.

It was found that the practices carried out by hotels rigidly attached to rules as a means to obtain satisfactory external evaluations, profoundly affect the employees' behaviour, both in their work and social relations.

Social relationships among employees who work under direct supervision is difficult. For example, changing work shifts impede them from sustaining any kind of communication or exchanges enabling them to identify with each other. In addition, their private and family life is subordinated to weekly role shifts established on the basis of the policies of the company. The disruption in family life is not taken into consideration by management.

It was noted that in organizations with confidence in employees' performance, there were greater integration into the organization and more socialization. As a result, there was a sharing of ideas, knowledge and know-how flowing naturally from the most experience staff members. It was noted how employees are involved in and committed to the aims of the organization while making decisions to meet customers' expectations. But above all, most of these workers were motivated to become part of the organization, and to take pride in achieving clearly stated goals.

The staff relationships in terms of functions in the production of services are characterized by decisions taken at the organizational apex, based on strategic monitoring of the options, which are operationalised by employees. Specialization of the worker is important in creating the power to apply those options.

If the objectives of the organization are not clear to the worker, there is little involvement of the latter. Efficiency at work is related to the sense of achievement of each employee but this will not occur if the objectives are not clear. This is clearly illustrated by emotional withdrawal and physical resistance to change to the innovations of the organization. The rigidity of the organization in terms of behavior that they bring to bear in their work areas, and the necessity of providing service twenty four hours a day, prevents socialization among workers.

Finally, while socializing in the workplace, employees make decisions according to the sense that the employees themselves give to quality and this is imbued with the values shared between them.

Decision-making in informal groups offers best results; it relies on camaraderie and cooperation even when people adhere to the existing range of alternatives for the company. 
Participation is proportional to the worker's fear of sanctions, he works only if there are no sanctions, but then he is not involved. The incentives of the organization go unnoticed. Contrary to that, the sympathy generated among members of the groups offers a better indicator of performance, as they seek options for making efficient processes based on the knowledge of the other members.

Findings will be valuable to understand how quality management with adherence only to the rules from an external environment affects the treatment of clients and of colleagues. As a result, the attitude of the workers is cold and hostile and, there are only exchanges of information in order to complete work processes.

\section{References}

Bendor J, Moe T. \& Shotts K., (2001) "Recycling the Garbage Can," American Political Science Review.

Del Castillo, Arturo (1996) El nuevo institucionalismo en el análisis organizacional: conceptos y enunciados explicativos. Documento de trabajo Núm. 44 CIDE División de Administración Pública.

Gamez, Rosalinda (2007) Comunicación y Cultura Organizacional en Empresas Chinas y Japonesas, http://www.eumed.net/libros/2007a/221/2v.htm, recuperado el 5 de febrero de 2007.

Maldonado, Ana (2007) Implicaciones socio-funcionales de la gestión de la calidad en el sector hotelero a nivel de los grupos de trabajo. Tesis, Universidad Autónoma Metropolitana Iztapalapa.

Meyer, John W. Y Brian Rowen (1999) "Organizaciones institucionalizadas: la estructura formal como mito y ceremonia”, Powell, Walter W. y Paúl J. DiMaggio (comps.), El nuevo Institucionalismo en el análisis organizacional, Fondo de Cultura Económica, México.

Molina, Sergio (1994) Modernización de empresas turísticas. Edit. CIENTUR, México.

Moreno, Maria Y Fernando Peris, Tomas González (2001) Gestión de la calidad y diseño de organizaciones. Teoría y estudio de casos, Prentice Hall. México.

Olsen, Johan (2001) "Garbage cans, new institutionalism, and the study of politics". In The American Political Science Review. Vol. 95 no. 1.

Powell, Walter Y Paul Dimaggio (2001) El nuevo institucionalismo en el análisis organizacional. Edit. Fondo de Cultura Económica, México.

Reeves, Carol, Bednar, David (1994) "Defining Quality". The Academy of Management Review, Vol. 19, No. 3 special issue: “total quality” (Jul., 1994), 419-445

Velarde, Mónica (2003) Modo de organización y estrategias de calidad en los servicios. El caso de una organización hotelera. Tesis, Universidad Autónoma Metropolitana Iztapalapa.

Zucker, Lynne (1982) "Institutional theories of organization", Annual review of sociology, Vol 13, 443-464 